\title{
Food Functionality of Popular and Commonly Consumed Indigenous Vegetables and Fruits from Bangladesh
}

\author{
M. M. Towhidul Islam¹, Arnab Talukder ${ }^{1}$, Taibur Rahman ${ }^{1}$, Jahid M. M. Islam², Shahdat Hossain ${ }^{3}$, \\ Hossain Uddin Shekhar ${ }^{1^{*}}$ \\ ${ }^{1}$ Department of Biochemistry and Molecular Biology, Faculty of Biological Sciences, University of Dhaka, Dhaka, Bangladesh; \\ ${ }^{2}$ Institute of Radiation and Polymer Technology, Bangladesh Atomic Energy Commission, Dhaka, Bangladesh; ${ }^{3}$ Department of Bio- \\ chemistry and Molecular Biology, Jahangirnagar University, Dhaka, Bangladesh. \\ Email: "hossainshekhar@yahoo.com, ${ }^{*}$ shekhardu@hotmail.com
}

Received April 27 $7^{\text {th }}, 2013$; revised May 28 ${ }^{\text {th }}, 2013$; accepted June $9^{\text {th }}, 2013$

Copyright (C) 2013 M. M. Towhidul Islam et al. This is an open access article distributed under the Creative Commons Attribution License, which permits unrestricted use, distribution, and reproduction in any medium, provided the original work is properly cited.

\begin{abstract}
Functional food can be either natural or processed. Food contains known biologically active compounds, which provides clinically proven and documented health benefit. So far, no database is available in Bangladesh regarding the functionality of the indigenous foods. As a primary step, this study had been conducted with an aim to identify and characterize functionality of the indigenous foods of Bangladesh. Eight fruits and vegetables, which are very popular for their taste, price and easy availability, have been selected for in vitro screening of their functionality. High levels of fat and sugar binding capacity were observed in Pineapple (500\% and $270.891 \%$ respectively). High nuplli mortality rate was found in cytotoxicity test with Pomelo extract (100\%), which also contained high level of vitamin C (155 $\mathrm{mg} / 100 \mathrm{~g})$. Pomelo contained the highest level of antioxidant among all these foods $(0.674 \mathrm{nMol} / 100 \mu \mathrm{l} / \mathrm{mg}$ protein). Red amaranth contained highest amount of protein $(4.31 \mathrm{~g} / 100 \mathrm{~g})$. In stem amaranth, Iron level was highest $(1855.67 \mathrm{mg} / \mathrm{kg})$. Total phenolics content of Water spinach and Stem amaranth were found higher than the other samples (59.339 and $55.728 \mathrm{mg} \mathrm{GAE} / \mathrm{g}$ respectively). All these experiments showed these vegetables and fruits have high health impacts and can be act as potential functional foods.
\end{abstract}

Keywords: Fruits; Vegetables; Indigenous Foods; Functional Foods; Anti-Oxidants; Health Benefits

\section{Introduction}

Functional food science is a new discipline that is part of nutrition science and is aimed at stimulating research and development of foods by using a function-driven approach. A food can be said to be functional if it contains a component (whether or not a nutrient) that benefits one or a limited number of roles of the body in a targeted way that is relevant to the state of well-being and health, like reduction of the risk of a disease or has physiologic or psychologic effect beyond the nutritional effect $[1,2]$. These concepts are particularly important in light of the increasing cost of health care, the steady increase in life expectancy, and the desire of older people for improved quality of their later years. Epidemiologic studies have also consistently shown that diet plays a crucial role in the prevention of chronic diseases [3-5]. Consumption of fruit and vegetables, as well as grains, has been strongly

${ }^{*}$ Corresponding author. associated with reduced risk of cardiovascular disease, cancer, diabetes, Alzheimer disease, cataracts, and agerelated functional decline [6]. It is estimated that one third of all cancer deaths in the United States could be avoided through appropriate dietary modification $[3,7,8]$.

Functional foods have important features like increased fat and sugar binding capacity, anti oxidative properties and others. For example, Lipid peroxidation is one of the principal causes of food quality deterioration that results in the formation of reactive oxygen species and free radicals; which are purportedly associated with carcinogenesis, mutagenesis, inflammation, aging and cardiovascular diseases [9]. Thus it is very necessary to suppress lipid peroxidation in food in order to preserve flavor, color and nutritional value [10]. A lot of studies have analyzed the antioxidant potential of a wide variety of vegetables, including cacao beans, potato, tomato, spinach, and legumes such as Phaseolus vulgaris and these compounds have been attributed, in a large part, to 
their scavenging of free radicals, chelating of transition ions and/or modulating antioxidant properties within cells [11]. Thus, health-conscious consumers are increasingly looking for foods that help control their own health and well-being. This growing search for a balanced diet in maintaining health has contributed to encourage research into new biologically active natural components and has changed our understanding of the importance of diet in good health. This study aims at in vitro primary screening of some popular, cheaply available indigenous fruits and vegetables to understand their food functionality.

\section{Methods \& Materials}

\subsection{Place of Study}

The study was conducted in various places under the supervision of Department of Biochemistry \& Molecular Biology, University of Dhaka. Main experiments were performed in Department of Biochemistry \& Molecular Biology, University of Dhaka; Food Technology Laboratory, Center for Advance Research in Science, University of Dhaka; Food Safety Laboratory, Bangladesh Center for Scientific and Industrial Research; and in Bangladesh Atomic Energy Commission, Savar, Dhaka.

\subsection{List of Foods under Study}

Eight commonly consumed Bangladeshi foods were collected and subjected to extraction. The name of the fruits and vegetables (following the order Bangladeshi name, English name, Scientific name) were: Amra (Hog PlumSpondiasdulcis), Jambura (Pomelo-Citrus maxima), Anaras (Pineapple-Ananascomosus), Kolmishak (Water spinach-Ipomoea aquatic), Lalshak (Red amaranthAmaranthusgangeticus), Kamranga (Carambola-Averrhoacarambola), Datashak (Stem amaranth-Amaranthuslividus), Korolla (Bitter gourd-Momordicacharantia).

\subsection{Sample Preparation}

Raw and fresh fruits and vegetables were collected from local market, weighted and then dehydrated by freezing (BUCHI Rotavapor R-114, Switzerland). Each of 300 gram of these fruits and vegetables were also taken and were extracted using Ethanol, n-Hexane, Chloroform, and Water. These extracts were then converted to powder form for further analysis.

\subsection{Analysis Performed}

\subsubsection{Determination of Fat Binding Capacity (FBC), Sugar Binding Capacity (SBC)}

FBC of was measured using a modified method of Wang and Kinsella [12]. In brief, Ethanolic food extracts were at first mixed with soyabean oil and mixed with the help of a vortex machine (VM-2000, Digisystem Laboratory
Instruments Inc., Taiwan) to disperse the sample. After centrifugation the supernatant was decanted, the tube was weighed to identify amount of fat bound to the extract.

SBC was measured by incubating ethanolic food extract with glucose sample as previously described [13].

\subsubsection{Determination of Cytotoxic Property and Vitamin C, Protein and Iron Content}

In vitro Cytotoxicity Test was performed using Brine Shrimp Lethality Bioassay method as described previously [14]. Previous method for Raw and fresh samples was also used to determine Vitamin C by HPLC [15]. Food protein content was determined by method described by Pellett and Young [16,17]. Iron contents of the samples were determined by Flame Atomic Absorption Spectrophotometer with previously described method [18].

\subsubsection{Determination of Lipid Peroxidation}

Male Long Evans rats (6 weeks of age) were purchased from Bangladesh Council of Scientific and Industrial Research (BCSIR), Dhaka. All the rats were housed in plastic cages (bedding was wood chips) and acclimatized to the laboratory conditions ( $12 \mathrm{~h} \mathrm{light/dark} \mathrm{cycle)} \mathrm{for} 7$ days prior to the commencement of the treatment. The rats in this study were cared for and sacrificed in accordance with the ethical norms approved by Bangladesh Association for Laboratory Animal Science. After treatment, the animals were sacrificed and livers were removed. Then livers were perfused with ice-cold saline to remove blood. These tissues were homogenized in phosphate buffer (50 mM, pH 7.4) using Dounce glass homogenizer (the USA). Lipid peroxidation was determined by estimating the thiobarbituric acid reactive substances (TBARs) according to the method of Ohkawa [19].

\subsubsection{Determination of Total Phenolics Content}

To measure total phenolics contents of the extracts, previously described method was used without modification [20].

\subsection{Data Analysis}

All analysis for samples were carried out in triplicate and expressed as mean value with their standard error. Graphs were generated using Microsoft Excel 2007 (Microsoft Corporation). For statistical analysis, Statistical Package for Social Science (SPSS, version 17.0, IBM Company) was used.

\section{Results}

\subsection{Fat Binding Capacity}

The Fat binding capacities (FBC) of the samples are shown in a Bar diagram. Pineapple, Stem amaranth, and 
Water spinach samples had high fat binding capacity. But in Hog Plum and Red amaranth, the capacity was observed in much lower amount (Figure 1).

\subsection{Sugar Binding Capacity}

Pineapple, Stem amaranth, Pomelo and Carambola possessed high level of Sugar Binding Capacities. And the SBC of Water spinach was lowest among all (Figure 2).

\subsection{In Vitro Cytotoxicity Test}

In the first figure Mortality rate (\%) of the Brine shrimp nauplii in the presence of $0.01 \mathrm{mg} / \mathrm{ml}$ dose of sample extracts. Vincristine sulfate was used as positive control at $0.5 \mathrm{mg} / \mathrm{ml}$ dose, whereas artificial saline water was served as Negative control. In this experiment Pomelo showed very high cytotoxic property as $100 \%$ mortality rate was achieved by it. Other extracts showed a mortality rate $\leq 30 \%$. The third Figure shows the Mortality rate (\%) of the Brine shrimp nauplii in the presence of 0.1 $\mathrm{mg} / \mathrm{ml}$ dose of sample extracts. Again Pomelo showed very high cytotoxicity as indicated by $100 \%$ mortality rate. But other extracts showed a mortality rate $\leq 60 \%$ (Figures 3(a) and (b)).

\subsection{Vitamin C Content}

Pomelo contains the highest amount of Vitamin C among all samples and Water spinach contains the lowest amount

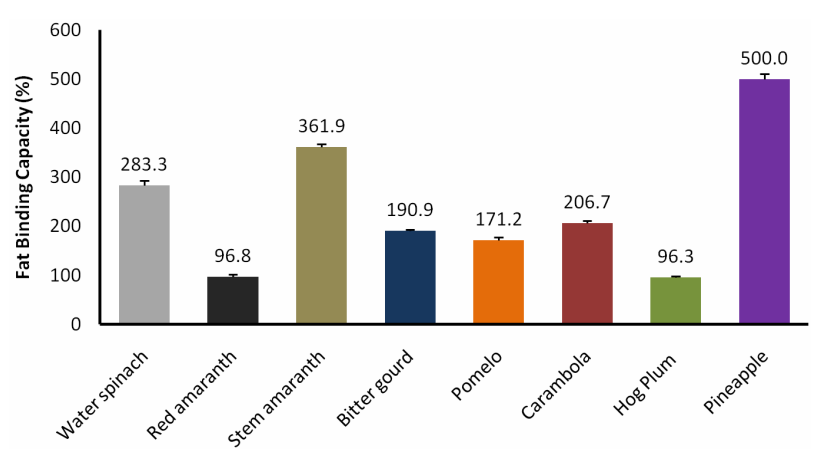

Figure 1. Fat Binding Capacity of the samples (\%).

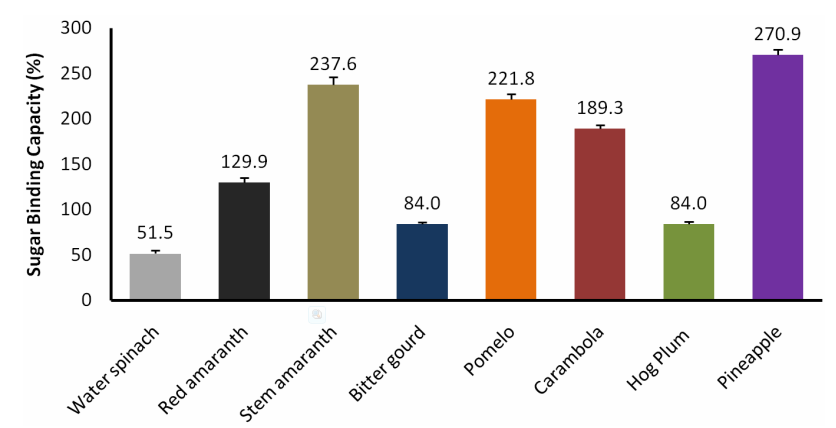

Figure 2. Sugar (glucose) binding capacity (\%) of the samples.
(Figure 4).

\subsection{Protein Content}

The figure represents the protein contents of the samples using a Bar diagram. Here, Red amaranth contains the highest amount of protein among all and Pomelo contains the lowest (Figure 5).

\subsection{Iron Content}

High amount of Iron was found in Stem amaranth, Water spinach, Red amaranth and Bitter gourd. But Pomelo, Carambola, Hog Plum and Pineapple possess low amount of Iron (Figure 6).

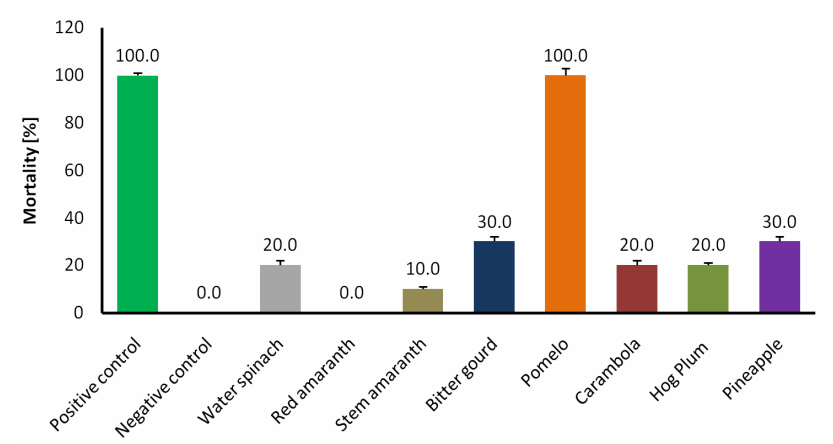

(a)

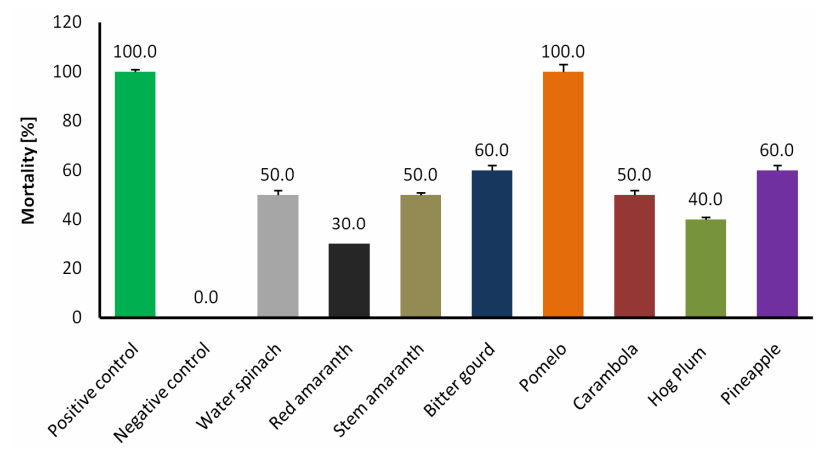

(b)

Figure 3. (a) Mortality rate (\%) of brine shrimp nauplii at $0.01 \mathrm{mg} / \mathrm{ml}$ dose; (b) Mortality rate of (\%) brine shrimp nauplii at $0.1 \mathrm{mg} / \mathrm{ml}$ dose.

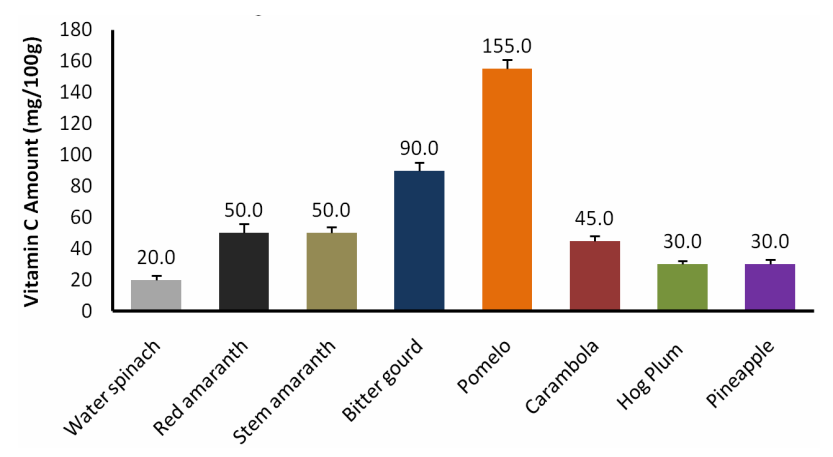

Figure 4. Vitamin C contents of the samples (mg/100g). 


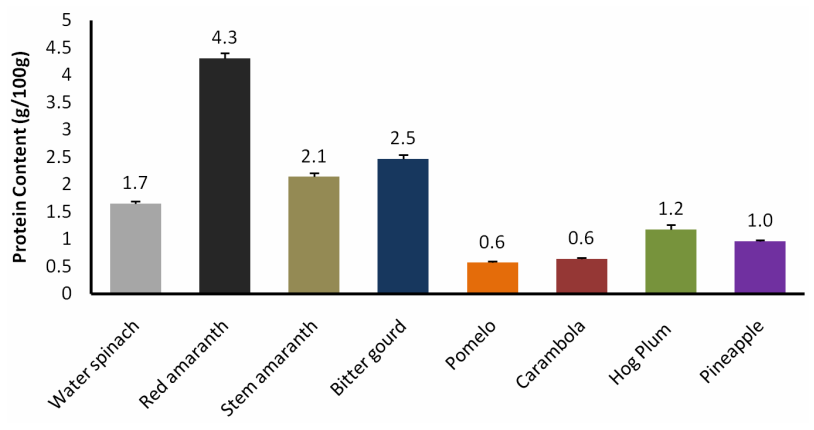

Figure 5. Protein contents of the samples (g/100g).

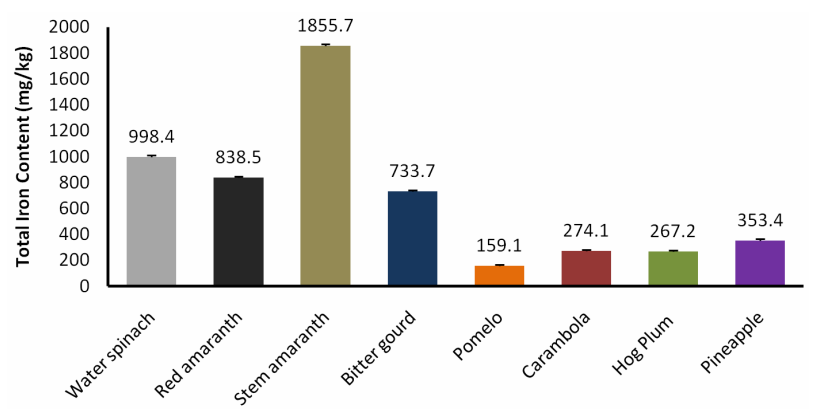

Figure 6. Iron contents of the samples $(\mathrm{mg} / \mathrm{kg})$.

\subsection{Antioxidant Property}

In the following figure, the LPO levels of different liver tissue homogenate were given. In the OS sample, only oxidative stress was present in the tissue homogenate, so that high level of Lipid peroxide (LPO) was found. And in the test samples, food extracts were given in the tissue homogenate with induced oxidative stress. It was found that Red amaranth, Pineapple and Pomelo extracts are capable of lowering the LPO level significantly (Figure 7).

\subsection{Total Phenolics Content}

The figure showed total phenolics contents of the samples in a Bar diagram (Figure 8).

Here, Water spinach and Stem amaranth contain high amount of total phenolics. The amount of total phenolics in Red amaranth, Bitter gourd, Pomelo and Carambola were also higher. Pineapple contains the lowest amount of total phenolics among all the samples.

\section{Discussion}

Bangladeshi indigenous fruits, grains, vegetables etc. had been reported to have immense therapeutic and medicinal values [21,22], but no systematic approach had been made to generate a functional food database so far. Thus as a first step some commonly used parameters, to judge food functionality, were analyzed, like Moisture content, Fat and Glucose binding capacity of foods, Cytotoxicity

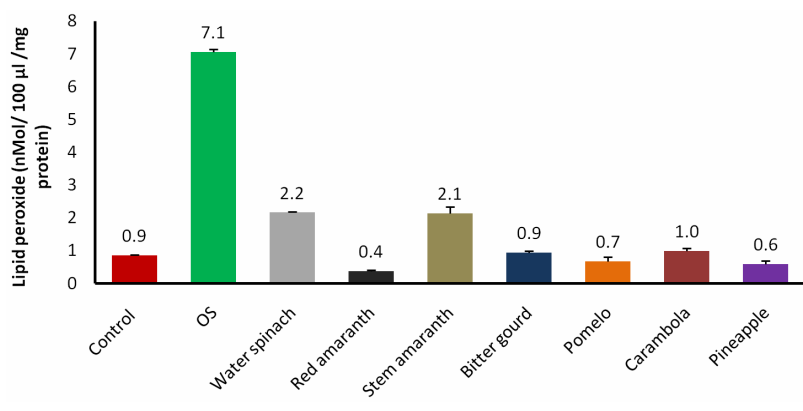

Figure 7. LPO concentrations (nMol/100 $\mathrm{\mu l} / \mathrm{mg}$ protein).

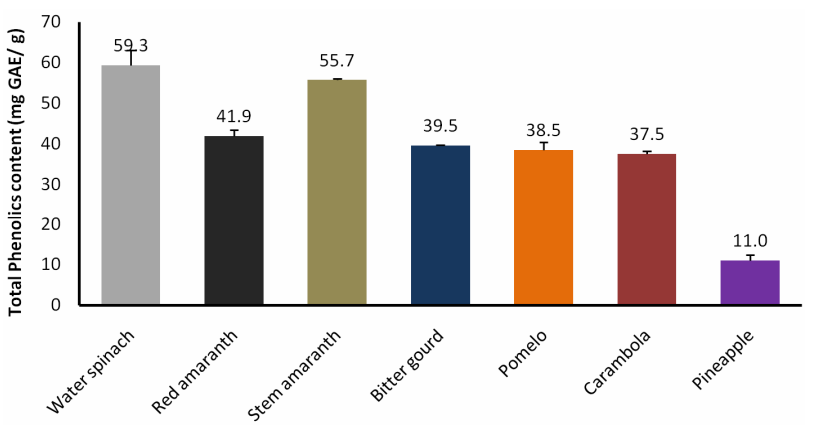

Figure 8. Total phenolics contents of the samples (mg GAE/g).

of that food, Antioxidant content, Micro and Macro nutrient content.

Optimum moisture content is necessary for a food's freshness and nutritional balance. Also, food industries require a minimum or maximum percentage of moisture on certain foods in order to pack and/or label [23]. In this study it was found that the moisture content of Hog Plum was the lowest $(84.5 \%)$. And the moisture content of Bitter gourd was the highest (92.25\%) (data not shown). This means that by eating these foods, one can feel fuller on a smaller amount of calories than foods with less water content. Therefore, these are excellent foods for losing weight or maintaining current weight. Another health benefit is that they help to keep skin hydrated, which leads to healthy, glowing skin.

Determination of FBC is essential for the discovery of anti obesity property in food. In this study it was found that the FBC of Pineapple was the highest (500\%) among all the samples under study. The FBC of Stem amaranth was also found high $(361.9 \%)$. And the $\mathrm{FBC}$ of $\mathrm{Hog}$ Plum was the lowest $(96.3 \%)$ ). It was found that fat binding capacity of patented fibre complex from Opuntiaficusindica was only $72 \%$, which is much lower than these indigenous Bangladeshi foods (www.proactol.com). So it can be stated that Pineapple and Stem amaranth have huge potentials against obesity (Figure 1).

Sugar Binding Capacity determines the sugar removal ability of a food from a system and can be used against high blood sugar level of a diabetic patient [24]. In this study, it was found that Pineapple, Stem amaranth and 
Pomelo have potential sugar binding capacity: $270.891 \%$, $237.6237 \%$ and $221.7821 \%$ respectively. And the lowest SBC was found in Water spinach (51.49\%). As in Bangladesh there is a high prevalence of Diabetics, so these samples can be considered as new dimension to control high blood sugar level at a low cost for developing countries (Figure 2).

Cytotoxicity determination helps to detect the ability of a sample to destroy cells. This functionality helps to determine anti tumor and chemotherapeutic agents [14]. In the study, it was found that, Pomelo has a very strong cytotoxic property with $100 \%$ mortality rate. And the lowest activity was found in Red amaranth $(0 \%)$. It indicates the presence of cytotoxically active compounds in Pomelo at a significant quantity. In future it will be further investigated to see whether these are more cytotoxic to the abnormal cells than to the normal cells or not (Figure 3).

Ascorbate is a vital nutrient and acts as cofactor of enzymes or antioxidant against oxidative stress [25]. In the study, it was found that, Pomelo had a very high level of Vitamin C $(155 \mathrm{mg} / 100 \mathrm{~g})$. Also this was true for Bitter gourd $(90 \mathrm{mg} / 100 \mathrm{~g})$. Lowest amount was found in Water spinach $(20 \mathrm{mg} / 100 \mathrm{~g})$. Among them Red and Green Hot Chili Peppers contained highest Vitamin C (242 mg/100g). As these study foods contain high amount of Vitamin C (the recommended daily allowance of Vitamin $\mathrm{C}$ is 75 $90 \mathrm{mg}$ ), they may be used to cure arthritis and other jointrelated diseases or pain, fight against age-related memory loss, macular degeneration, cataracts and other eyesight problems - complications very much common among the people aged 65 or over in Bangladesh (Figure 4).

Protein is an important macronutrient. Among all the vegetables and fruits Bracken $(20 \mathrm{~g} / 100 \mathrm{~g})$ and Apricot $(9.2 \mathrm{~g} / 100 \mathrm{~g})$ contain highest amount of proteins

(http://www.wholefoodcatalog.info). In the study, it was found that, Red amaranth has the highest level of protein among all other samples $(4.31 \mathrm{~g} / 100 \mathrm{~g})$. And the lowest amount of protein was found in Pomelo $(0.57 \mathrm{~g} / 100 \mathrm{~g})$. As proteins are necessary in animals' diets, it is speculated that these available country foods may help to fulfill the protein requirements of Bangladeshi poor people, to whom it is very difficult to buy costly protein rich foods (Figure 5).

Iron is an essential micronutrient and key component of many proteins in the study, it was found that, Stem amaranth contains very high level of Iron $(1855.67 \mathrm{mg} /$ $\mathrm{kg}$ ). Also Water spinach, Red amaranth and Bitter gourd have significant levels of iron content: $998.41 \mathrm{mg} / \mathrm{kg}$, $838.46 \mathrm{mg} / \mathrm{kg}$ and $733.68 \mathrm{mg} / \mathrm{kg}$ respectively. The lowest amount of Iron was found in Pomelo $(159.09 \mathrm{mg} / \mathrm{kg})$. It is estimated that, Men need around $8 \mathrm{mg}$ of iron in their daily diet and women need up to $18 \mathrm{mg}$ (or $27 \mathrm{mg}$ if pregnant) (www.betterhealth.vic.gov.au). Even though these low requirements iron deficiency Anemia is very much prevalent in Bangladesh. So, these high iron containing study foods can play a vital role against iron deficiency anemia (Figure 6).

Lipid peroxidation refers to the oxidative degradation of lipids and may cause hemolysis by rupturing red blood cell membranes [26]. In addition, end-products of lipid peroxidation may be mutagenic and carcinogenic [27]. It was found that, Glutathione peroxidase 4 (GPX4) knockout mice do not survive past embryonic day 8 , indicating that the removal of lipid hydroperoxides is essential for mammalian life [28]. In this research it was studied that whether the food extracts under study inhibite lipid peroxidation or not. On basis of the results of thiobarbituric acid reactive substance (TBARS) assay, this study clearly indicates that all the food extracts under study decreased the level of LPO. Among them, Red amaranth, Pineapple and Pomelo decreased the LPO level noticeably. The LPO level of the oxidative stress induced sample was $7.064 \mathrm{nMol} / 100 \mu 1 / \mathrm{mg}$ protein. But the levels of LPO in the samples containing the extracts of Red amaranth, Pineapple and Pomelo were 0.383, 0.599, and 0.674 $\mathrm{nMol} / 100 \mu \mathrm{l} / \mathrm{mg}$ protein respectively. So these food extracts have strong anti oxidative properties and are capable of lowering LPO level considerably and thus can be used to minimize stress and oxidative radical mediated injuries in a cost effective way (Figure 7).

Natural phenols are small molecules containing one or more phenolic group. Most are known to have an antioxidant activity and give protection against heart disease and cancer. That's why foods containing natural phenols are generally considered as health food. In the study, it was found that, Water spinach and Stem amaranth had a high level of total phenolics contents: 59.339 and 55.728 mg GAE/gm extract respectively. And Pineapple had the lowest phenolics content among all: $11.006 \mathrm{mg} \mathrm{GAE} / \mathrm{gm}$ extract. These data suggests that Water spinach and Stem amaranth can be consider as health food (Figure 8).

From this study it was observed that the most promising functional foods are Red amaranth, Pomelo and Pineapple. When we statistically analyze these data, it was found that there were significant correlation between Iron content with protein content $(\mathrm{p}=0.04)$ and with phenollics content $(p=0.02)$. We also found that a significant negative correlation between LPO content and sugar binding capacity to each other $(p=0.007)$. These results suggests that indigenous foods of Bangladesh can be act as potential functional food and there functionality may depends on other property of that food also. We will plan to test these foods in vivo for further analysis (like to identify their anti-diabetic, anti-carcinogenic, anti hypertensive properties). 


\section{Acknowledgements}

This work had been funded by follow up research grant of the United Nation University (UNU)-Kirin for fellows of session-2010-11. The Authors expressed their sincere gratitude to the authorities of the National Food Research Institute (NFRI),2-1-12 Kannondai, Tsukuba, Ibaraki 305-8642, Japan for their all out support.

\section{REFERENCES}

[1] M. B. Roberfroid, "Concepts and Strategy of Functional Food Science: The European Perspective," The American Journal of Clinical Nutrition, Vol. 71, No. 6, 2000, pp. 1660S-1664S.

[2] F. M. Clydesdale, "A Proposal for the Establishment of Scientific Criteria for Health Claims for Functional Foods," Nutrition Reviews, Vol. 55, No. 12, 1997, pp. 413-422. doi:10.1111/j.1753-4887.1997.tb01588.x

[3] R. H. Liu, "Health Benefits of Fruit and Vegetables Are from Additive and Synergistic Combinations of Phytochemicals," The American Journal of Clinical Nutrition, Vol. 78, No. 3, 2003, pp. 517S-520S.

[4] N. Temple, "Antioxidants and Disease: More Questions than Answers," Nutrition Research, Vol. 20, No. 3, 2000, pp. 449-459. doi:10.1016/S0271-5317(00)00138-X

[5] W. C. Willett, "Diet and Health: What Should We Eat?" Science, Vol. 264, No. 5158, 1994, pp. 532-537.

[6] W. C. Willett, "Diet, Nutrition, and Avoidable Cancer," Environmental Health Perspectives, Vol. 103, No. S8, 1995, pp. 165-170.

[7] R. Doll and R. Peto, "The Causes of Cancer: Quantitative Estimates of Avoidable Risks of Cancer in the United States Today," Journal of the National Cancer Institute, Vol. 66, No. 6, 1981, pp. 1191-1308.

[8] Assembly of Life Sciences (US), Committee on Diet Nutrition, and Cancer, "Diet, Nutrition, and Cancer," National Academy Press, Washington DC, 1982.

[9] B. Halliwell, "Lipid Peroxidation, Antioxidants and Cardiovascular Disease: How Should We Move Forward?" Cardiovascular Research, Vol. 47, No. 3, 2000, pp. 410418.

[10] A. J. St. Angelo, et al., "Lipid Oxidation on Foods," Critical Reviews in Food Science and Nutrition, Vol. 36, No. 3, 1996, pp. 175-224. doi:10.1080/10408399609527723

[11] V. Lobo, A. Patil, A. Phatak and N. Chandra, "Free Radicals, Antioxidants and Functional Foods: Impact on $\mathrm{Hu}-$ man Health," Pharmacognosy Reviews, Vol. 4, No. 8, 2010, pp. 118-126.

[12] J. C. Wang and J. E. Kinsella, "Functional Properties of Novel Proteins: Alfalfa Leaf Protein," Journal of Food Science, Vol. 41, No. 2, 1976, pp. 286-292. doi:10.1111/j.1365-2621.1976.tb00602.x

[13] A. B. Blakeney and L. L. Mutton, "A Simple Colorimetric Method for the Determination of Sugars in Fruit and Vegetables," Journal of the Science of Food and Agricul- ture, Vol. 31, No. 9, 1980, pp. 889-897. doi:10.1002/jsfa.2740310905

[14] M. N. Khan, J. M. M. Islam and M. A. Khan, "Fabrication and Characterization of Gelatin-Based Biocompatible Porous Composite Scaffold for Bone Tissue Engineering," Journal of Biomedical Materials Research, Vol. 100A, No. 11, 2012, pp. 3020-3028. doi:10.1002/jbm.a.34248

[15] Y. Shimada and S. Ko, "Quantitative Determination of Ascorbic Acid in Vegetables by High-Performance Liquid Chromatography," Chugokugakuen Journal, Vol. 5, 2006, pp. 13-16.

[16] FAO, "Amino Acid Content of Foods and Biological Data of Proteins," 2nd Edition, Food Science Service, Rome, 1970.

[17] L. P. Pellett and V. R. Young, "Nutritional Evaluation of Protein Foods," United Nation University, Tokyo, 1980.

[18] T. E. Siang, K. S. Chao and S. M. Shahid, "Determination of Iron in Foods by the Atomic Absorption Spectrophotometric and Colorimetric Methods," Pertanika, Vol. 12, No. 3, 1989, pp. 313-322.

[19] H. Ohkawa, N. Ohishi and K. Yagi, "Assay for Lipid Peroxides in Animal Tissues by Thiobarbituric Acid Reaction," Analytical Biochemistry, Vol. 95, No. 2, 1979, pp. 351-358. doi:10.1016/0003-2697(79)90738-3

[20] Y. Hilal and U. Engelhardt, "Characterisation of White Tea-Comparison to Green and Black Tea," Journal of Consumer Protection and Food Safety, Vol. 2, No. 4, 2007, pp. 414-421.

[21] H. U. Shekhar, "Functional Foods from Bangladesh: Food Functionality of Bangladeshi Vegetables and Rice (High Yielding and Traditional Varieties)," LAP LAMBERT Academic Publishing, Saarbrücken, 2012.

[22] H. U. Shekhar, M. Goto, J. Watanabe, I. Konishide-Mikami, M. L. Bari and Y. Takano-Ishikawa, "Multi Food Functionalities of KalmiShak (Ipomoea aquatica) Grown in Bangladesh," Agriculture, Food and Analytical Bacteriology, Vol. 1, No. 1, 2011, pp. 24-32.

[23] C. Schuna, "Importance of Moisture Content in Foods," 2012.

http://www.ehow.com/facts_5865278_importance-moistu re-content-foods.html

[24] R. Aller, D. A. de Luis, O. Izaola, F. La Calle, L. del Olmo, L. Fernandez, et al., "Effect of Soluble Fiber Intake in Lipid and Glucose Levels in Healthy Subjects: A Randomized Clinical Trial," Diabetes Research and Clinical Practice, Vol. 65, No. 1, 2004, pp. 7-11. doi:10.1016/j.diabres.2003.11.005

[25] S. Kharb and V. Singh, "Nutriceuticals in Health and Disease Prevention," Indian Journal of Clinical Biochemistry, Vol. 19, No. 1, 2004, pp. 50-53. doi:10.1007/BF02872389

[26] E. M. Ostrea, E. E. Cepeda, C. A. Fleury and J. E. Balun, "Red Cell Membrane Lipid Peroxidation and Hemolysis Secondary to Phototherapy," Actapaediatrica Scandinavica, Vol. 74, No. 3, 1985, pp. 378-381. doi:10.1111/j.1651-2227.1985.tb10987.x

[27] L. J. Marnett, "Lipid Peroxidation-DNA Damage by Malondialdehyde," Mutation Research, Vol. 424, No. 1-2, 
1999, pp. 83-95. doi:10.1016/S0027-5107(99)00010-X

[28] F. L. Muller, M. S. Lustgarten, Y. Jang, A. Richardson and H. Van Remmen, "Trends in Oxidative Aging Theo- ries," Free Radical Biology \& Medicine, Vol. 43, No. 4, 2007, pp. 477-503.

doi:10.1016/j.freeradbiomed.2007.03.034 